\title{
Design of a novel quantitative PCR (QPCR)-based protocol for genotyping mice carrying the neuroprotective Wallerian degeneration slow (Wlds) gene
}

\author{
Thomas M Wishart*1,2, Stephen HF MacDonald³, Philip E Chen², \\ Michael J Shipston ${ }^{1}$, Michael P Coleman ${ }^{4}$, Thomas H Gillingwater ${ }^{1,2}$ and \\ Richard R Ribchester ${ }^{2}$
}

Address: ${ }^{1}$ Centre for Integrative Physiology, University of Edinburgh, Hugh Robson Building, George Square, Edinburgh, UK, ${ }^{2}$ Centre for Neuroscience Research, University of Edinburgh, Hugh Robson Building, George Square, Edinburgh, UK, ${ }^{3}$ Trinity Institute of Molecular Medicine, St. James's Hospital, Dublin 8, Ireland and ${ }^{4}$ Laboratory of Molecular Signalling, Babraham Institute, Babraham, Cambridge, UK

Email: Thomas M Wishart* - T.M.Wishart@ed.ac.uk; Stephen HF MacDonald - macdonas@tcd.ie; Philip E Chen - p.chen@ed.ac.uk; Michael J Shipston - Mike.Shipston@ed.ac.uk; Michael P Coleman - michael.coleman@bbsrc.ac.uk;

Thomas H Gillingwater - T.Gillingwater@ed.ac.uk; Richard R Ribchester -rrr@ed.ac.uk

* Corresponding author

Published: 30 October 2007

Molecular Neurodegeneration 2007, 2:21 doi:10.1186/1750-|326-2-21
Received: 12 September 2007

Accepted: 30 October 2007

This article is available from: http://www.molecularneurodegeneration.com/content/2/I/2I

(c) 2007 Wishart et al; licensee BioMed Central Ltd.

This is an Open Access article distributed under the terms of the Creative Commons Attribution License (http://creativecommons.org/licenses/by/2.0), which permits unrestricted use, distribution, and reproduction in any medium, provided the original work is properly cited.

\begin{abstract}
Background: Mice carrying the spontaneous genetic mutation known as Wallerian degeneration slow (W/ds) have a unique neuroprotective phenotype, where axonal and synaptic compartments of neurons are protected from degeneration following a wide variety of physical, toxic and inherited disease-inducing stimuli. This remarkable phenotype has been shown to delay onset and progression in several mouse models of neurodegenerative disease, suggesting that WIds-mediated neuroprotection may assist in the identification of novel therapeutic targets. As a result, crossbreeding of WIds mice with mouse models of neurodegenerative diseases is used increasingly to understand the roles of axon and synapse degeneration in disease. However, the phenotype shows strong gene-dose dependence so it is important to distinguish offspring that are homozygous or heterozygous for the mutation. Since the WIds mutation comprises a triplication of a region already present in the mouse genome, the most stringent way to quantify the number of mutant WIds alleles is using copy number. Current approaches to genotype WIds mice are based on either Southern blots or pulsed field gel electrophoresis, neither of which are as rapid or efficient as quantitative PCR (QPCR).
\end{abstract}

Results: We have developed a rapid, robust and efficient genotyping method for WIds using QPCR. This approach differentiates, based on copy number, homozygous and heterozygous WIds mice from wild-type mice and each other. We show that this approach can be used to genotype mice carrying the spontaneous WIds mutation as well as animals expressing the WIds transgene.

Conclusion: We have developed a QPCR genotyping method that permits rapid and effective genotyping of Wlds copy number. This technique will be of particular benefit in studies where WIds mice are cross-bred with other mouse models of neurodegenerative disease in order to understand the neuroprotective processes conferred by the WIds mutation. 


\section{Background}

The Wallerian degeneration slow gene (Wlds) protects axons and synapses in both the CNS and PNS from injury, neurotoxin- and inherited neurodegenerative conditions [1-5]. These properties have been shown to mitigate disease progression in several mouse models of neurodegenerative disease, including certain forms of motor neuron disease [[6,7]; but see [8]], gracile axonal dystrophy [9], Parkinson's disease [10], transient global cerebral ischemia [11], and myelin-related axonopathies [12]. Moreover, this remarkable neuroprotective phenotype has been transferred to other species, including rats and Drosophila $[13,14]$. The ability to deliver the Wlds gene to wildtype cells and confer neuroprotection across different species offers the possibility of developing Wlds-based therapeutics for treating human disease [5,13,15-17].

Evidence from studies of natural mutant mice and mice transgenic for Wld ${ }^{S}$ suggests that its neuroprotective effect is strongly gene-dose dependent. For instance, reducing Wlds protein expression by $50 \%$ removes almost all of the protective effect on motor nerve terminals while further reductions in the expression level additionally weakens the protection of distal axons $(3,18)$. As cross-breeding of $W l d^{s}$ mice with other mouse models of neurodegenerative disease becomes more commonplace, the ability to identify and distinguish wild-type from heterozygous and homozygous mice becomes more critical.

The Wlds mutation is a triplication of a region already present in the wild-type animal, encoding a fusion protein comprising the full length of nicotinamide mononucleotide adenylyltransferase 1 (Nmnat 1 ; a NAD ${ }^{+}$synthesizing enzyme) coupled by a unique 18 -amino acid sequence to the $\mathrm{N}$-terminal 70 residues of the ubiquitination enzyme Ube $4 \mathrm{~b}[18,19]$. Therefore, the means available to assess the number of mutant $W l d^{S}$ alleles present are by using either, the strength of the neuroprotective phenotype (for instance, based on protection of axons and synapses following a surgical nerve lesion) or detecting the copy number of the mutation. As well as an inefficient use of resources, the first approach is not suitable for genotyping on ethical and temporal grounds: an invasive procedure (nerve injury or biopsy) is required to test for strength of neuroprotection over a period of several days and provides only an indirect and semi-quantitative measure. The second approach is therefore the only one suitable for exact genotyping purposes.

Initially, attempts to PCR across the chimeric boundary were unreliable due to the very high GC content at that point in the sequence [20]. Some success was found through the use of Southern blots in identifying homozygous animals from heterozygous animals as it can be used to some extent to distinguish the genotype by band intensity [20]. However, Southern blotting proved to be an inefficient method for this type of genotyping as the results were often influenced by the need for equivalent loading concentrations, inconsistent DNA digestions, problems with blotting efficiency, and other factors that affected the quantifiable intensity of blots, their signalnoise ratio and the ability of the researcher to distinguish between samples on a film. A more robust method for genotyping $\mathrm{Wld}^{S}$ mice was also reported by $\mathrm{Mi}$ and colleagues [20] based on Pulsed Field Gel Electrophoresis (PFGE). The PFGE method is based on fragment size rather than band intensity. Problems with this approach include the requirement for post-mortem material (not ideal for cross-breeding programs), time taken to obtain data and the requirement for the use of radio-labelled probes.

Here we report the development of a novel QPCR genotyping method that will allow rapid and effective genotyping of Wlds copy number.

\section{Results and discussion Quantitative PCR (QPCR) on genomic DNA for genotyping WIds mice}

C57BL/6J and C57BL/Wlds mice were obtained from Harlan UK and, where required were cross-bred to obtain F1 mice, heterozygous for Wlds. Ear punches were taken from mice between 1 and 4 months of age $(\mathrm{N}=36$ of confirmed genotype, $\mathrm{N}=91$ of unknown genotype). Tail tips were taken from transgenic rat lines $\operatorname{Tg} 23(\mathrm{~N}=10)$ and $\operatorname{Tg} 79(\mathrm{~N}=14)$. The investigator carrying out the QPCR screen was always blinded to the genotype of each tissue sample.

Genomic DNA was extracted using a modified proteinase $\mathrm{K}$ digestion/isopropanol precipitation protocol [21]. Tissue was incubated in tail lysis buffer $(100 \mathrm{mM}$ Tris- $\mathrm{HCl}$, pH 8.5, 5 mM EDTA, 0.2\% SDS, $200 \mathrm{mM} \mathrm{NaCl}, 100 \mu \mathrm{g} /$ $\mathrm{ml}$ Proteinase K). Samples were incubated overnight at $55^{\circ} \mathrm{C}$. Lysed tissue was vortexed for 1 minute and spun at $15800 \mathrm{~g}$ for 10 minutes to remove hair and bone. The supernatant was decanted into a new tube and isopropanol was added (equal volume to the tail lysis buffer used earlier). The solutions were inverted until a white precipitate was seen. The solution was centrifuged and the pelleted DNA was washed with $70 \%$ ethanol and air dried before it was resuspended in an appropriate volume of 1 $\times$ TE buffer. For example, a $5 \mathrm{~mm}$ length of tail tip was digested and the DNA was finally resuspended in $50 \mu \mathrm{l}$ of TE buffer and then stored at $-20^{\circ} \mathrm{C}$ as a stock solution.

The primers and probes (TaqMan Probes) were designed using Primer Express software as described in the $\mathrm{ABI}$ Primer Express User Bulletin ( $\mathrm{P} / \mathrm{N}$ 4317594). Wlds primers were based on Genbank entry AF260927 and recognise 
and amplify bases $810-885$ of the $W l d^{s}$ chimeric gene (Figure 1). The Wlds probe was tagged with a FAM fluorophore and a TAMRA quencher. The product of the Wlds reaction is a $75 \mathrm{bp}$ amplicon. $\beta$-Tubulin primers were based on Genbank entry M28739. The probe was tagged with a VIC fluorophore and a TAMRA quencher. The product of the $\beta$-Tubulin reaction is an $81 \mathrm{bp}$ amplicon. The sequences (5'-3') used were as follows:

\section{Wlds forward GGCAGTGACGCTCAGAAATTC}

\section{Wlds reverse GTTCACCAGGTGGATGTTGCT}

Wlds probe TCTACGAGTCCGATGTGCTGTGGAGACA

\section{$\beta$-Tubulin forward GCCAGAGTGGTGCAGGAAATA}

$\beta$-Tubulin reverse TCACCACGTCCAGGACAGAGT

$\beta$-Tubulin probe CTGGGCAAAGGGCCACTACACAGAG

G

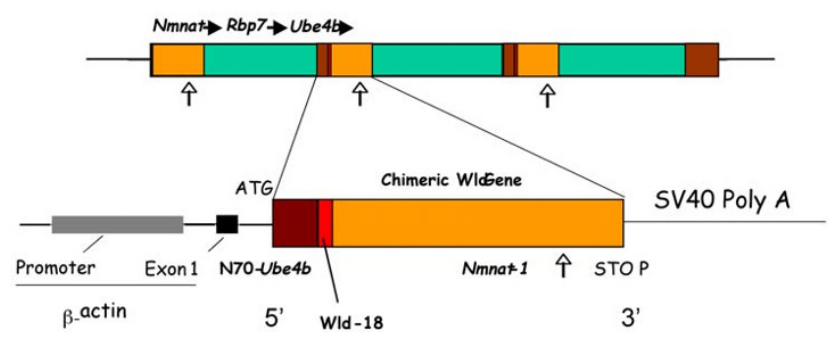

\section{Figure I}

The WIds mutation and transgene. The spontaneous mutation discovered in the WIds mouse and the transgene used to make the various transgenic WIds animals including Tg4836 mouse, Tg23 and Tg79 rat lines. The triplication results in the Wlds mouse having one full copy of Nmnat I (shown in orange) and Ube4b (shown in brown) at either ends if the triplicated region. Within the triplicated region are 2 copies of an in frame fusion of the N70 amino acids of Ube $4 b$ linked to the whole coding region of Nmnat I leading to the expression of 18 amino acids which are normally contained within the $5^{\prime}$ untranslated region of $\mathrm{Nmnat} /$ (termed WId-I 8 shown in red) which has been used for antibody targeting. Primers against the WIds sequence were designed to amplify bases 810-885 in the Genbank sequence AF260927 that correspond to a portion of the Nmnat-I sequence in the chimeric WIds product. Arrows indicate approximate site of amplification on the gene schematic. Figure modified from Gillingwater et al., 2006 [17].
A serial dilution of genomic DNA from wild-type C57Bl/ $6 \mathrm{~J}$ mice was used as a template for PCR to test the efficiency of amplification of the two primer pairs. The genomic DNA was diluted 1 in 10 each time and correlation coefficients were obtained for each primer pair (Figure 2). PCR efficiency was calculated by plotting the Threshold cycle (Ct) as a function of $\log 10$ concentration of the template used (Figure 2; $\mathrm{x}$-axis plotted as - $\log \mu \mathrm{g}$ DNA. See Applied Biosystems website for user bulletin \#2 [22]). The slope of the trend line produced is a function of PCR efficiency, with a slope of -3.32 indicating close to $100 \%$ efficiency [22]. Standard curves suggested efficient amplification of both primer sets, as indicated by correlation coefficients and linear regression slopes. Primers against a region of $W l d^{s}$ and $\beta$-tubulin gave correlation coefficients of 0.9989 and 0.9928 respectively, with slopes of -3.455 for $\beta$-tubulin and -3.3647 for Wlds (Figure 2). The reactions were found to proceed similarly when primers were used both separately and together, indicating that the two separate primer pairs do not interact with each other. Once this had been demonstrated, genotyping reactions were reliably performed containing both sets of primers and probes in the same well.

The optimal primer concentrations used were $900 \mathrm{nM}$ and the optimal probe concentration was found to be $250 \mathrm{nM}$. The PCR mix (TaqMan universal PCR master mix, no amperase UNG from ABI part \# 4364341) was prepared according to the manufacturer's instructions. $1 \mu$ l of DNA was used at a concentration of 1:200 dilution (in TE buffer) of the original stock sample for each reaction. All reactions were carried out in triplicate on an ABI Prism

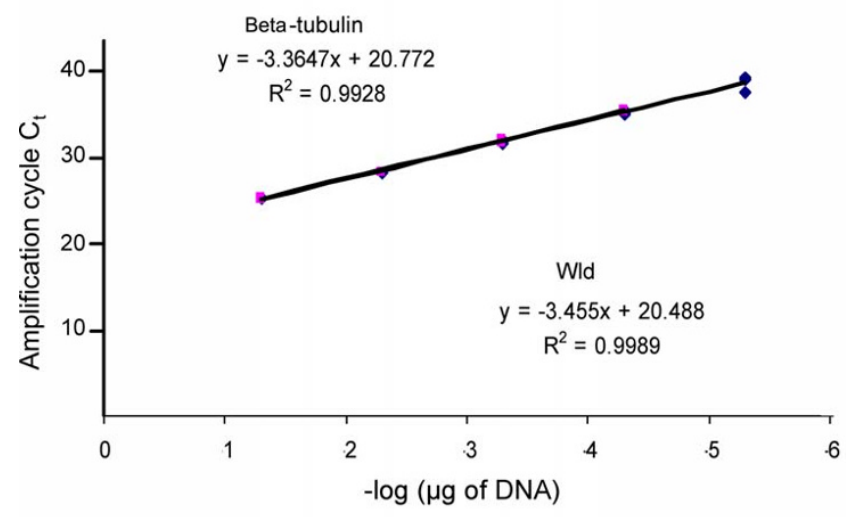

\section{Figure 2}

Primers for WIds and $\beta$-tubulin have very similar $\mathbf{R}^{2}$ values. Standard curves for the WIds and $\beta$-tubulin gene in a serially diluted ( $\mathrm{I}$ in 10$)$ template genomic DNA sample from wild-type (C57B//6)). Efficient amplification was obtained for both sets of primers, as demonstrated by the slopes of linear regression of the standard curves, and good correlation coefficients. $C_{t}$ is cycle threshold. 
7000 sequence detection system using Applied Biosystems' standard thermal cycling parameters.

The product of a PCR for the Wlds amplicon alone run on an ethidium bromide stained gel showed that bands from each genotype could not be distinguished from each other (data not shown). However, the $2^{-\Delta \Delta C T}$ method (for more detail see Applied Biosystems website for user bulletin \#2), using $\beta$-tubulin as an endogenous control and $W l d^{s}$ as a calibrator, allowed determination of copy number. Amplification plots for wild-type, heterozygous-Wlds and
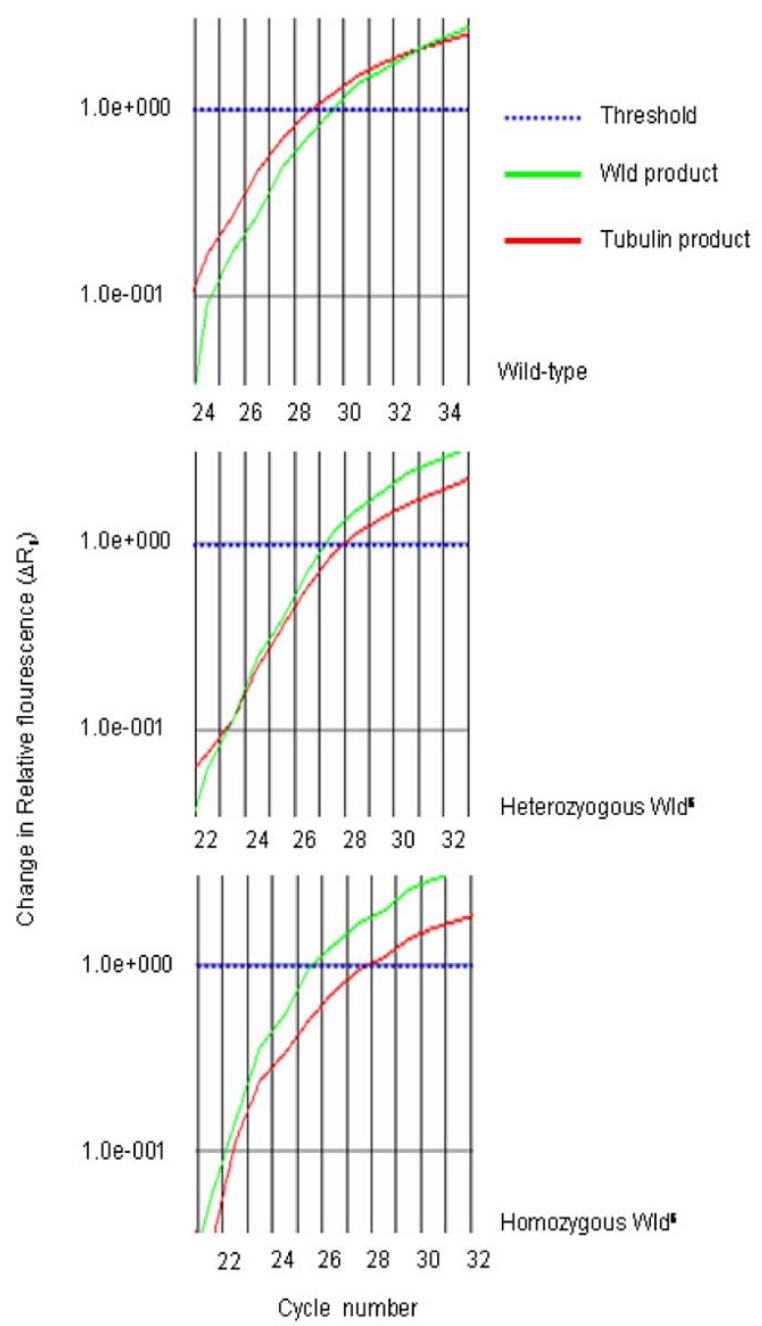

Figure 3

Real time data shows differences between wild-type, heterozygous and homozygous animals. Screen grabs from $A B I$ software. The curves show the difference in cycle number $\left(\Delta C_{t}\right)$ between tubulin (pseudo-coloured red) and WIds (pseudo-coloured green) for each genotype at the set threshold (1.0e+000, pseudo-coloured blue). These are representative curves only and should be viewed in conjunction with Figure 4.
homozygous-Wlds showed clear differences for the $\Delta \mathrm{C}_{\mathrm{T}}$ between each group (Figure $3 \& 4$ ). The difference between $\beta$-tubulin and Wlds amplicon product at the set threshold can be used to determine $W l d^{s}$ genotype. A wild-type mouse gives a mean cycle difference of $-0.40( \pm 0.26 \mathrm{SD})$ with $95 \%$ confidence limits of $-1.04 \&+0.24$. A mouse heterozygous for $W l d^{s}$ gives a mean cycle difference of $1.07( \pm 0.32 \mathrm{SD})$ with $95 \%$ confidence limits of $+0.97 \&$ +1.17 . A mouse homozygous for $W l d^{s}$ gives mean cycle difference of 2.07 ( $\pm 0.30 \mathrm{SD})$ with $95 \%$ confidence limits of $+01.995 \&+2.158$ (Figure 4 ).

Plotting the $\Delta \mathrm{C}_{\mathrm{t}}$ against animals of known genotype in a box and whisker plot $(\mathrm{N}=36)$ allows the illustration of 95\% confidence limits for each genotype (Figure 4). When plotting a scatter of the results for all of the animals of unknown genotype $(\mathrm{N}=91)$ there was a clear banding into the 3 genotypes as demonstrated by the box and whisker plot of animals of known genotype (Figure 4). Only one sample fell outwith the 95\% confidence limits for all of the plotted genotypes shown (Figure 4). In such circumstances, the genotyping for this particular sample should be considered invalid. The Wlds status of a representative set of unknown genotype animals whose identity was determined by QPCR was successfully confirmed using breeding records, Southern blotting techniques and subsequent experiments where the neuroprotective phenotype was revealed by nerve lesion and the use of morphological techniques (data not shown).

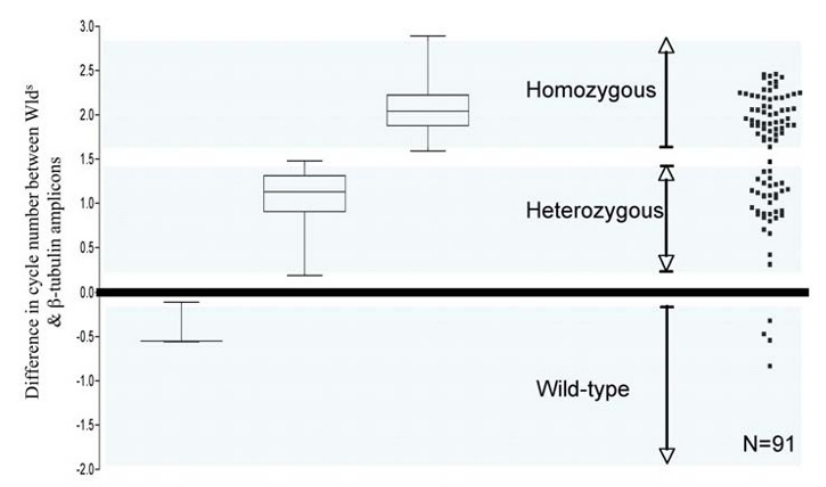

Figure 4

QPCR on genomic DNA shows clear difference in $\Delta \mathbf{C}_{t}$ for the 3 genotypes. A graphical representation of $\Delta \mathrm{C}_{\mathrm{t}}$ between the tubulin and Wld amplicons, for animals of known genotype ( $N=36$, box and whisker) and animals of unknown genotype ( $N=91$, scatter). The areas shown in blue represent the $95 \%$ confidence limits for each particular genotype as determined from the box and whisker plots. There is a clear trend for each particular genotype. 


\section{Determining copy number in transgenic animals}

Transgenic animals (mice and rats) have been generated which express the $W l d^{s}$ chimeric gene $[13,18]$. These animals show a strong neuroprotective phenotype. As it has previously been shown that the Wlds neuroprotective phenotype is dose-dependent (see above), it is therefore of interest to determine the number of copies which have been integrated into the genome of these transgenic animals.

We examined 2 rat models of Wlds: the transgenic line 23 and transgenic line 79 [13]. Through the use of QPCR on genomic DNA (utilising the $2^{-\Delta \Delta C T}$ method described above) it is possible to calculate the copy number of insertions into the rat genome. The results examining the number of inserts in two of the Wlds transgenic lines can be seen in Figure 5. There was additional variability in the amplification process at higher copy number with QPCR, as previously described when using this technology [22]. However, the data show that transgenic rat lines 23 and 79 contain $12.34 \pm 2.05(\mathrm{~N}=10)$ and $19.49 \pm 1.52(\mathrm{~N}=14)$ copies of the Wlds gene respectively, significantly more than homozygous $W l d^{s}$ mice, as would be expected in transgenic animals generated using non-targeted insertion. It is also important to note that the data do not give

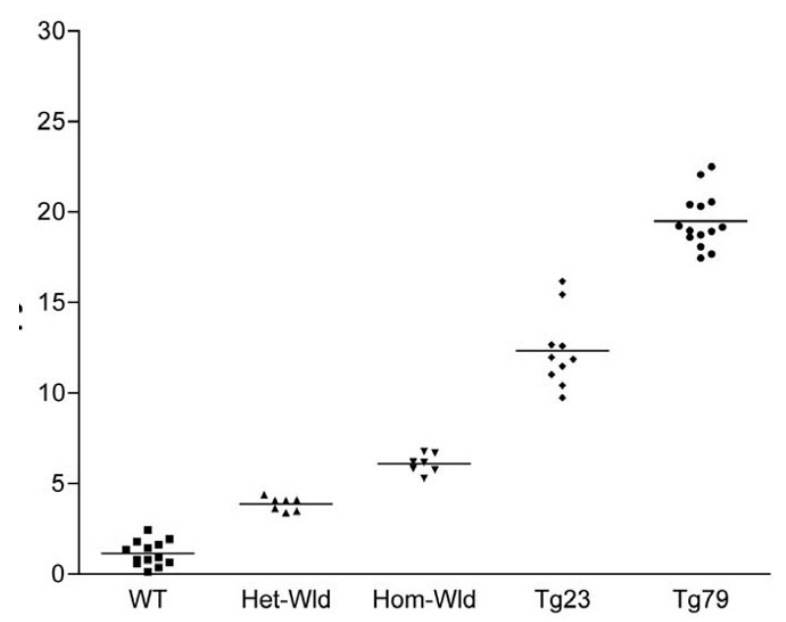

Figure 5

QPCR can be used to determine copy number in transgenic animals. QPCR carried out on samples of genomic DNA can be used to determine copy number of an insert in rat transgenic lines $(\mathrm{Tg}) 23$ and 79. Although there is some fluctuation in the determined copy number, wild-type (WT) animals are expected to have 2 copies. Heterozygous WIds (Het-WId) are expected to have 4 copies and homozygous WIds (Hom-Wld) should have 6 copies. Analysis of the QPCR data showed the following copy numbers: WT I.I5 \pm 0.68 (mean \pm SEM) copies $(N=13)$, Het-WId $3.87 \pm$ 0.36 copies $(\mathrm{N}=7)$, Hom-Wld $6.10 \pm 0.53$ copies $(\mathrm{N}=7)$, Tg23 I2.34 $\pm 2.05(\mathrm{~N}=10)$ and Tg79 19.49 $\pm 1.52(\mathrm{~N}=14)$. any indication of transgene orientation or functionality. Despite this, the increase Wlds copy number in the transgenic rats tallies with previously reported increases in phenotypic strength compared to homozygous Wlds mice [13].

It is especially important to measure $W l d^{S}$ copy number and expression level before making conclusions about its effects when attempting to transfer protective benefits to models of disease. For instance, two reports suggest little or no mitigation of disease onset or progression after crossbreeding Wlds mice with mouse models of amyotrophic lateral sclerosis $(8,15)$; but it is presently unclear whether these reports fully accounted for the known, weak synaptic-protective effects of the $W l d^{S}$ gene in heterozygous and aged mice $(3,18)$.

\section{Conclusion}

The QPCR genotyping method we report here facilitates accurate, rapid and effective genotyping of $W l d^{s}$ copy number in both spontaneous mutant mice and transgenic animals expressing $W l d^{s}$, representing an improved, cost effective and more efficient general purpose method than PFGE, the most accurate alternative method reported thus far. This methodology should be of interest to groups working on other mutations which are difficult to genotype as the DNA does not need to be accurately quantified before use. This is because the methodology works by examining ratios between PCR product of interest and controls rather than absolute levels. It is also applicable to smaller tissue samples such as ear punches. This technique will be of particular benefit for current and future studies where Wlds mice or their transgenic equivalents, are being crossed with other strains, and especially relevant for studies attempting to understand the relationship between gene-dosage of the $W l d^{s}$ mutation and the effectiveness of its neuroprotective phenotype.

\section{Competing interests}

The author(s) declare that they have no competing interests.

\section{Authors' contributions}

TMW designed and carried out the experiments, analysed data and drafted the manuscript. SHFM helped design primers and optimise reaction efficiency. PEC designed experiments. MPC generated and provided transgenic material. THG and RRR participated in study design and drafted the manuscript. All authors read and approved the final manuscript.

\section{Acknowledgements}

The authors would like to thank Derek Thomson for expert technical assistance. This work was supported by grants from the BBSRC (TMW/ THG/MPC/MJS), MRC (RRR) and the Wellcome Trust (MPC/RRR/MJS). 


\section{References}

I. Lunn R, Perry VH, Brown MC, Rosen H, Gordon S: Absence of wallerain degeneration does not hinder regeneration in peripheral nerve. European Journal of Neuroscience I989, I:27-33.

2. Ribchester RR, Tsao JW, Barry JA, Asgari-Jirhandeh N, Perry VH, Brown MC: Persistance of neuromuscular junctions after axotomy in mice with slow Wallerian degeneration (C57BL/ WIds). European Journal of Neuroscience 1995, 7:|64|-1650.

3. Gillingwater TH, Thomson D, Mack TG, Soffin EM, Mattison RJ, Coleman MP, Ribchester RR: Age dependant synapse withdrawal at axotomised neuromuscular junctions in WId(s) mutant and Ube4b/Nmnat transgenic mice. J Physiol 2002, 543:739-755.

4. Wang MS, Davis AA, Culver DG, Glass JD: WIds mice are resistant to paclitaxel (Taxol) neuropathy. Ann Neurol 2002, 52:442-447.

5. Gillingwater TH, Ingham CA, Parry KE, Wright AK, Haley JE, Wishart TM, Arbuthnott GW, Ribchester RR: Delayed synaptic degeneration in the CNS of WIds mice after cortical lesion. Brain 2006, I 29: I546-I556.

6. Ferri A, Sanes JR, Coleman MP, Cunningham JM, Kato AC: Inhibiting axon degeneration and synapse loss attenuates apoptosis and disease progression in a mouse model of motorneurone disease. Current Biology 2003, 13:669-673.

7. Fischer LR, Culver DG, Davis AA, Tennant P, Wang M, Coleman M, Asress S, Adalbert R, Alexander GM, Glass JD: The WIdS gene modestly prolongs survival in the SODIG93A fALS mouse. Neurobiol Dis 2005, 19:293-300.

8. Vande Velde MM, Garcia ML, Yin X, Trapp BD, Cleveland DW: The neuroprotective factor WIds does not attenuate mutant SODI-mediated motor neurone disease. Neuromolecular Ned 2004, 5: 193-203.

9. Mi W, Beirowski B, Gillingwater TH, Adalbert R, Wagner D, Grumme D, Osaka H, Conforti L, Arnhold S, Addicks K, Wada K, Ribchester RR, Coleman MP: The slow Wallerian degeneration gene, WIdS, inhibits axonal spheroid pathology in gracile axonal dystrophy mice. Brain 2005, I 28:405-16.

10. Sajadi A, Schneider BL, Aebischer P: WIds-mediated protection of dopinergic fibres in an animal model of Parkinson disease. Current Biology 2004, 14:326-330.

II. Gillingwater TH, Haley JE, Ribchester RR, Horsborough K: Neuroprotection after transient global ischaemia in WId(s) mutant mice. I Cereb Blood Flow Metab 2004, 24:62-66.

12. Samsam M, Mi W, Wessig C, Zielasek J, Toyka KV, Coleman MP, Martini $R$ : The WIds mutation delays robust loss of motor and sensory axons in a genetic model for myelin-related axonopathy. Journal of Neuroscience 2003, 23:2833-2839.

13. Adalbert R, Gillingwater TH, Haley JE, Bridge K, Beirowski B, Berek L, Wagner D, Grumme D, Thomson D, Celik A, Addicks K, Ribchester RR, Coleman MP: A rat model of slow Wallerian degeneration (WIdS) with improved preservation of synapses. European Journal of Neuroscience 2005, 2 I :27l-7.

14. MacDonald JM, Beach MG, Porpiglia E, Sheehan AE, Watts RJ, Freeman MR: The Drosphila cell corpse engulfment receptor Draper mediates glial clearance of severed axons. Neuron 2006, 50:869-88I.

15. Wang MS, Fang G, Culver DG, Davis AA, Rich MM, Glass JD: The WIds protein protects against axonal degeneration: a model of gene therapy for peripheral neuropathy. Annules of Neurology 200I, 50:773-779.

16. Wishart TM, Paterson JM, Short DM, Meredith S, Robertson KA, Sutherland C, Cousin MA, Dutia MB, Gillingwater TH: Differential proteomic analysis of synaptic proteins identifies potential cellular targets and protein mediators of synaptic neuroprotection conferred by the slow Wallerian degeneration (WIds) gene. Mol Cell Proteomics 2007, 6:13 I8-1330.

17. Gillingwater TH, Wishart TM, Chen PE, Haley JE, Robertson K, MacDonald SH, Middleton S, Wawrowski K, Shipston MJ, Melmed S, Wyllie DJ, Skehel PA, Coleman MP, Ribchester RR: The neuroprotective WIdS gene regulates expression of PTTG I and erythroid differentiation regulator I-like gene in mice and human cells. Hum Mol Genet 2006, I 5:625-635.

18. Mack TGA, Reiner M, Beirowski B, Mi W, Emanuelli M, Wagner D, Thomson D, Gillingwater T, Court F, Conforti L, Fernando FS, Tarlton A, Andressen C, Addicks K, Magni G, Ribchester RR, Perry VH, Coleman MP: Wallerain degeneration of injured axons and synapses is delayed by a Ube 4 b/Nmnat chimeric gene. Nature Neuroscience 2001, 4:1199-1206.
19. Conforti L, Tarlton A, Mack TGA, Mi W, Buckmaster EA, Wagner D, Perry VH, Coleman MP: A Ufd2/D4Cole le chimeric protein and overexpression of Rbp7 in the slow Wallerian degeneration (WIdS) mouse. PNAS 2000, 97: I I 377- I I 382.

20. Mi W, Conforti L, Coleman MP: Genotyping Methods to Detect a Unique Neuroprotective Factor (WIds) for Axons. Journal of Neuroscience Research 2002, I I3:2 I5-2 I8.

21. Laird PW, Zijderveld A, Linders K, Rudnicki MA, Jaenisch R, Berns A: Simplified mammalian DNA isolation procedure. Nucleic Acids Research 1991, 19:4293-4297.

22. Ballester M, Castello A, Sanchez A, Folch JM: Real-time quantitative PCR based system for determining transgene copy number in transgenic animals. BioTechniques 2004, 37:610-613.
Publish with Bio Med Central and every scientist can read your work free of charge

"BioMed Central will be the most significant development for disseminating the results of biomedical research in our lifetime. "

Sir Paul Nurse, Cancer Research UK

Your research papers will be:

- available free of charge to the entire biomedical community

- peer reviewed and published immediately upon acceptance

- cited in PubMed and archived on PubMed Central

- yours - you keep the copyright

Submit your manuscript here:

http://www.biomedcentral.com/info/publishing_adv.asp
BioMedcentral 